\title{
The Impacts of Childhood and Adolescent Obesity on Quality of Life
}

\begin{abstract}
Obesity is important and its affects are not only limited to adults and medicalconditions, but also may affect children and adolescents and may have overarching effects on social parameters. Programs to prevent the negative outcomes associated with obesity and its associated social stigmization should be at the forefront. And, lastly, both medical and surgical options to prevent and combat obesity should be investigated as there is often a positive association with an improvement in body mass index and health related quality of life.
\end{abstract}

\section{Introduction}

Health-Related Quality of Life (HRQOL) is a multi-dimensional term and it involves factors such as physical, social, mental, emotional and overall social functioning [1]. HRQOL is a measurement of how a medical condition, in this case obesity, impacts a person's life in a reproducible physical or mental manner [1,2]. Albeit, this can be difficult in children and adolescents to have reproducible results; yet, we know that obesity leads to decreased social interactions and functional impairment that progress from childhood into adulthood $[2,3]$. One such cross-sectional analysis found that older adolescents were more likely to ascribe feelings of functional impairment versus younger patients who ascribed more social and emotional impairment [3]. Therefore, the aim of studies and programs should be at addressing obesity and quality of life as one entity and preventing progression into adulthood understanding that one may have to use a tool, or proxy, that is easy to implement and is reproducible.

The way in which we, as healthcare professionals, address children and adolescents with regards to their weight as well as to classifications as overweight and obesity, also has a significant impact on the success of those individuals to eventually lose weight or maintain a healthy weight. In scientific terms, overweight and obesity has been defined as a body mass index (BMI) of between the $85^{\text {th }}$ and $95^{\text {th }}$ percentile for the former and greater than the $95^{\text {th }}$ percentile for the latter [4]. Yet, Puhl and associates have reported numerous times that there is a pervasive character to the association between weight bias on the part of healthcare professionals, stigmization of our youth and negative outcomes that is quite common among children and adolescents who are overweight and obese leading to poor health-related quality of life [5].

Obesity is a pandemic given the wide range of associated comorbid conditions as well as the predominant effects on quality of life [6-8]. Almost $1 / 5^{\text {th }}$ of the United States' population below the age of 20 are obese [9]; however, the regulatory agencies have not found appropriate evidence at this time to promote standardized screening for obesity-related conditions or standardized language on how to discuss the ways in which to ameliorate them [10].

\section{Journal of Obesity and Bariatrics}

\section{Sigrid Bairdain*}

Department of Pediatric Surgery, Boston Children's Hospital, Boston, Massachusetts, USA

\section{*Address for Correspondence}

Sigrid Bairdain, MD, MPH, Pediatric Surgery Research and Clinical Resident Boston Children's Hospital, Department of Pediatric Surgery 300 Longwood Avenue, Fegan Building, 3rd Floor Boston, Massachusetts 02115, USA, E-mail: Sigrid.bairdain@childrens.harvard.edu

Copyright: (c) 2015 Bairdain S. This is an open access article distributed under the Creative Commons Attribution License, which permits unrestricted use, distribution, and reproduction in any medium, provided the original work is properly cited.

Submission: 20 January 2014

Accepted: 25 February 2015

Published: 01 March 2015

Reviewed \& Approved by: Dr. Yishai Levy, Clinical Associate

Professor, Technion Faculty of Medicine, Israel

\section{Cardiovascular and Metabolic Risk Factors}

Cardiovascular risk factors and cardiovascular disease is common among obese children and adolescents. Two recent studies have evaluated the impacts of obesity longitudinally on the cardiovascular system. One study evaluated the role of body mass index (BMI) as a surrogate measurement for vascular health in adults; the higher the BMI in childhood correlated with higher incidence of arthrosclerosis as adults [11]. On the other hand, another recently published article evaluated the effects of weight classes on cardiovascular entities such as pre-hypertension, hypertension, pre-diabetes, and diabetes [12]. From 1999-2008, their study group showed a significant increase in pre-diabetes and diabetes, but did not see as significant of an increase in such entities as pre-hypertension, hypertension or hyperlipidemia [12].

Overall, the effects of obesity on the cardiovascular system are not just limited to the United States and have become an issue for children in other countries, both in industrialized and developing countries. For example, one-third of sample in a Canadian province had unfavourable cardiovascular risk factors [13]. Various studies reflect on whether this ultimately has an effect on premature morality [14,15]; however it continues to cause unseen morbidity. These diseases cost society and healthcare enormously given their longitudinal nature and propensity to worsen over time with a reduction in quality of life [15-18]. For example, one study suggests that, with respect to Type 2 diabetes and obesity, the associated reduction in HRQOL is the sum of the individual disease entities [19].

Metabolic syndrome has also become pandemic in children and adolescents. Those children and adolescents with a high amount of visceral fat, intrahepatic fat and intramyocellular fat may be at the highest risk for metabolic syndrome and/or the concurrent development of Type 2 diabetes mellitus [20,21]. Previous work has cited the clustering of cardiovascular risk factors (hypertension, abdominal adiposity, dyslipidemia, and altered glucose metabolism) as the hallmark of the syndrome with or without obesity [22]. Both the lipid partitioning and alterations in the level of glycosylated haemoglobin are related to disease related complications and the degree of health related quality of life issues in diabetes specifically 
$[21,22]$. Therefore, it is imperative to prevent the development of metabolic syndrome and Type 2 diabetes mellitus in children and adolescents given the duration of the disease, as well as the potential incidence of complications, will only heighten the associated decrease in health-related quality of life aspects.

Hyperlipidemia, as part of the metabolic syndrome, or in isolation is also more prevalent in overweight and obese children and adolescent. There have been fewer studies on the direct correlation between dysplipidemia and health-related quality of life. However, it appears that dyslipidemia exerts its affects either through its association with metabolic syndrome or its association with cardiovascular implications. For example, in one study, there appeared to be a direct correlation between change in BMI, obesity in adulthood and associated dyslipidemia, as well as associated cardiovascular morbidities [22].

\section{Respiratory System}

There is also growing evidence that there is a negative interaction between obesity and the respiratory system. A more recent national study illustrated the association with excess weight and nonatopic asthma with obese children and adolescents having a higher incidence of non-atopic asthma [23]. Obstructive sleep apnea is also increased. One study found that almost $40 \%$ of overweight children had symptoms suggestive of obstructive sleep apnea [24]. Obstructive sleep apnea may not only lead to physical complications such as decreased oxygen saturation and associated right heart strain, but may also lead to daytime sleepiness, decreased productivity at school and work, and decreased ability to function $[23,24]$.

\section{Orthopedic}

Obese children report more joint pain with subsequent loss of function and associated depression [25-28]. This loss of function results in either missed school days in younger children and/or potentially missed work in older adolescents. Overall, orthopaedic concerns result in pain and disability, limited productivity, and a decrease in overall quality of life [25]. However, unlike adults, increased weight in children and adolescent may also lead to issues in their development and have permanent life-long effects independent of whether they eventually lose weight. Some of these entities include Tibia vera and Slipped Capital Femoral Ephysis (SCFE) where the former results in remodelling of the lower extremity and the latter results in remodelling of the hip and femoral head; both of these entities may require surgery.

\section{Mental Health}

As a whole, most studies performed on obesity and mental health has been performed in adults; however, more recent data has suggested that children and adolescents face the same difficulties with depression, anxiety and social stigma [29]. The National Longitudinal Study of Adolescent Health suggested that older adolescents face more limitations with physical functioning, whereas younger adolescents face issues with depression, self-esteem and poor school functioning [3]. The link between obesity and mental health is not as simple as older versus younger children, but is also modified by such factors as age, gender, ethnicity and race, as well as structural constructs [29].

Historically, these characteristics may pose the highest risk for mental health concerns in obese children and adolescents including: younger children and adolescents; lower socioeconomic status; females; and black children and adolescents [29]. There may be structural constraints, there may be structural constructs that also may potentiate mental health and stigma associated with obesity. Short-term and long-term psychological and social development of obese children and adolescents are often mitigated by either positive constructs at school or, more likely, negatively by school bullying [30]. This may be tempered by support provided by either positive cultural support and/or positive attitude of peers and family [31].

\section{Cost and Treatment}

Evidence does suggest that weight loss does have a positive impact on health related quality of life; albeit this is tempered by the amount of data as well as duration of its affects [32]. Weight loss surgeries in adults improve quality of life; fewer studies exist in the pediatric literature to make that same statement emphatically [33]. Very few children and adolescents have undergone weight loss surgeries given concern about timing of surgeries and normal development, as well as associated catastrophic surgical complications; some studies quote that only $2 \%$ of the pediatric population have been offered the opportunity to undergo weight loss surgery [34].

The overall economic consequences of obesity during both childhood and adolescence are equally concerning and growing dramatically. Obese children and adolescents have greater health care utilization that translates to almost $\$ 14.1$ billion in additional health care costs annually [35]. Concurrently, obesity-associated annual hospital costs have increased more than threefold from 1979 to 1999 [36]. Failing to reverse the obesity epidemic will result in declining quality of life and productivity for a large percentage of the population with subsequent economic costs and obesity- associated morbidity.

Weight management strategies have been evaluated with youth; some, primarily comprehensive behavioural interventions, show modest short term benefits [37]. Pharmacologic treatments have also been used as adjuncts to weight loss treatments in adolescents; however, the data are limited, yield small reductions in BMI, and also have adverse side effects [37].

Bariatric surgery has been associated with the largest reductions in weight and reversal of comorbid conditions in adults as compared to intensive medical programs $[38,39]$ In juxtaposition, surgical options still remain somewhat a controversial for children and adolescents [40,41] Preliminary information though, from the TEENLongitudinal Assessment of Bariatric Surgery (TEEN-LABS) study group, has shown safe perioperative profiles, encouraging shortterm data for weight loss, and resolution of co-morbid conditions [42] Furthermore, Inge et al. found that Weight-Related Quality of Life (WRQOL) is an important factor in the overall perioperative outcomes of adolescents and that BMI alone is not the primary determining factor [43]. Continued evaluation of factors supporting weight loss in youth, as well as maintenance is key.

\section{Future Directions}

Obesity in children and adolescents not only impacts physical functioning and medical co-morbidities, but also has a significant impact on emotional and social well-being. Its overall impact is not 
as fully defined as it is in adults; however, programs to prevent the negative outcomes associated with obesity and its associated social stigmization should be at the forefront. And, lastly, both medical and surgical options to prevent and combat obesity should be investigated as there is often a positive association with an improvement in body mass index and health related quality of life.

\section{References}

1. Healthy People 2020 (2010) Health-related quality of life and well-being Foundation Health Measure Report: 1-6.

2. Schwimmer JB, Burwinkle TM, Varni JW (2003) Health-related quality of life of severely obese children and adolescents. JAMA 289: 1813-1819.

3. Swallen KC, Reither EN, Haas SA, Meier AM (2005) Overweight, obesity, and health-related quality of life among adolescents: the national longitudinal study of adolescent health. Pediatrics 115: 340-347.

4. Ogden CL, Flegal KM (2010) Changes in the Terminology for Childhood Overweight and Obesity. Natl Health Stat Report 25: 1-5.

5. Puhl R, Latner J (2008) Weight bias: new science on a significant social problem. Introduction. Obesity (Silver Spring) 16: S1-S2.

6. Andersen RE (2000) The spread of the childhood obesity epidemic. CMAJ 163: $1461-1462$

7. Ebbeling CB, Pawlak DB, Ludwig DS (2002) Childhood obesity: public-health crisis, common sense cure. Lancet 360: 473-482.

8. Rocchini AP (2002) Childhood obesity and the diabetes epidemic. N Engl J Med 346: 854-855

9. Ogden CL, Carroll MD, Kit BK, Flegal KM (2012) Prevalence of obesity and trends in body mass index among US children and adolescents, 1999-2010. JAMA 307: 483-490.

10. Whitlock EP, O'Connor EA, Williams SB, Beil TL, Lutz KW (2010) Effectiveness of weight management interventions in children: a targeted systematic review for the USPSTF. Pediatrics 125: e396-e418.

11. Li S, Chen W, Srinivasan SR, Bond MG, Tang R, et al. (2003) Childhood cardiovascular risk factors and carotid vascular changes in adulthood: the bogalusa heart study. JAMA 290: 2271-2276.

12. May A, Kuklina EV, Yoon PW (2012) Prevalence of cardiovascular risk factors among US adolescents, 1999-2008. Pediatrics 129: 1035-1041.

13. Lambert M, Delvin EE, Levy E, O'Loughlin J, Paradis G, et al. (2008) Prevalence of cardiometabolic risk factors by weight status in a populationbased sample of Quebec children and adolescents. Can J Cardiol 24: 575583

14. Bjorge T, Engeland A, Tverdal A, Smith GD (2008) Body mass index in adolescence in relation to cause-specific mortality: a follow-up of 230,000 Norwegian adolescents. Am J Epidemiol 168: 30-37.

15. Park MH, Falconer C, Viner RM, Kinra S (2012) The impact of childhood obesity on morbidity and mortality in adulthood: A systematic review. Obes Rev 13: 985-1000.

16. Wolf AM, Colditz GA (1998) Current estimates of the economic cost of obesity in the United States. Obes Res 6: 97-106.

17. Ford ES, Li C (2008) Defining the MS in children and adolescents: will the real definition please stand up? J Pediatr 152: 160-164.

18. Messiah S, Mitnik-Lopez G, Winegar D, Sherif B, Arheart KL, et al. (2013) Changes in weight and co-morbidities among adolescents undergoing bariatric surgery: 1-year results from the Bariatric Outcomes Longitudinal Database. Surg Obes Relat Dis 9: 503-513.

19. Gough SC, Kragh N, Ploug UJ, Hammer M (2009) Impact of obesity and type 2 diabetes on health-related quality of life in the general population in England. Diabetes Metab Syndr Obes 3: 179-184.

20. Cali AM, Caprio S (2008) Obesity in children and adolescents. J Clin Endocrinol Metab 93: S31-S36.
21. Rejeski WJ, Lang W, Neiberg RH, Van Dorsten B, Foster GD, et al. (2006) Correlates of health-related quality of life in overweight and obese adults with type 2 diabetes Obesity (Silver Spring) 14: 870-883.

22. Weiss R, Bremer AA, Lustig RH (2013) What is metabolic syndrome, and why are children getting it? Ann N Y Acad Sci 128: 123-140.

23. Visness CM, London SJ, Daniels JL, Kaufman JS, Yeatts KB, et al. (2010) Association of childhood obesity with atopic and non-atopic asthma: results from the national health and nutrition examination survey 1999-2006. J Asthma 47: 822-829.

24. Mallory GB Jr, Fiser DH, Jackson R (1989) Sleep-associated breathing disorders in morbidly obese children and adolescents. J Pediatr 115: 892897.

25. Bout-Tabaku S, Briggs MS, Schmitt LC (2013) Lower Extremity pain is associated with reduced function and psychosocial health in obese children. Clin Orthop Relat Res 471: 1236-1244.

26. de Sá Pinto AL, de Barros Holanda PM, Radu AS, Villares SM, Lima FR (2006) Musculoskeletal findings in obese children. J Paediatr Child Health 42: 341-344.

27. Stovtiz SD, Parder PE, Vazquez G, Duval S, Schwimmer JB (2008) Musculoskeletal pain in obese children and adolescents. Acta Paediatr 97: 489-493.

28. Taylor ED, Theim KR, Mirch MC, Ghorbani S, Tanofsky-Kraff M, et al. (2006) Orthopedic Complications of overweight in children and adolescents. Pediatrics 117: 2167-2174.

29. Assari S (2014) The Link between Mental Health and Obesity: Role of Individual and Contextual Factors. Int J Prev Med 5: 247-249.

30. Janssen I, Craig WM, Boyce WF, Pickett W (2004) Associations between overweight and obesity with bullying behaviours in school-aged children. Pediatrics 113: 1187-1194.

31. Jari M, Qorbani M, Motlagh ME, Heshmat R, Ardalan G, et al. (2014) Association of overweight and obesity with mental distress in iranian adolescents: the CASPIAN-III study. Int J Prev Med 5: 256-261.

32. Tsiros MD, Olds T, Buckley JD, Grimshaw P, Brennan L, et al. (2009) Healthrelated quality of life in obese children and adolescents. Int J Obes 33: 387 400

33. Adams TD, Gress RE, Smith SC, Halverson RC, Simper SC, et al. (2007) Long-term mortality after gastric bypass. N Engl J Med 357: 753-761.

34. Oyetunji TA, Franklin AL, Ortega G, Akolkar N, Qureshi FG, et al. (2012) Revisiting childhood obesity: persistent underutilization of surgical intervention? Am Surg 78: 788-793.

35. Trasande L, Chatterjee S (2009) The impact of obesity on health service utilization and costs in childhood. Obesity (Silver Spring) 17: 1749-1754.

36. Wang G, Dietz WH (2002) Economic burden of obesity in youths aged 6 to 17 years: 1979-1999. Pediatrics 109: E81-81.

37. Whitlock EP, O'Connor EA, Williams SB, Beil TL, Lutz KW (2010) Effectiveness of weight management interventions in children: a targeted systematic review for the USPSTF. Pediatrics 125: e396-418.

38. Chakravarty PD, McLaughlin E, Whittaker D, Byrne E, Cowan E, et al. (2012) Comparison of laparoscopic adjustable gastric banding (LAGB) with other bariatric procedures; a systematic review of the randomised controlled trials. Surgeon 10: 172-182.

39. Lynch J, Belgaumkar A (2012) Bariatric surgery is effective and safe in patients over 55: a systematic review and meta-analysis. Obes Surg 22: 1507-1516. 
Citation: Bairdain S. The Impacts of Childhood and Adolescent Obesity on Quality of Life. J Obes Bariatrics. 2015;2(1): 4.

ISSN: 2377-9284

40. Garcia VF, Langford L, Inge TH (2003) Application of laparoscopy for bariatric surgery in adolescents. Curr Opin Pediatr 15: 248-255.

41. Starfield B, Riley AW, Green BF, Ensminger ME, Ryan SA, et al. (1995) The adolescent child health and illness profile. A population-based measure of health. Med Care 33: 553-566.

42. Inge TH, Zeller MH, Jenkins TM, Helmrath M, Brandt ML, et al. (2014)
Perioperative outcomes of adolescents undergoing bariatric surgery: the Teen Longitudinal Assessment of Bariatric Surgery (Teen-LABS) study. JAMA Pediatr 168: 47-53

43. Zeller MH, Inge TH, Modi AC, Jenkins TM, Michalsky MP, et al. (2015) Severe obesity and comorbid condition impact on the weight-related quality of life of the adolescent patient. J Pediatr 166: 651-659. 